\title{
Chitosan scaffolds with BMP-6 loaded alginate microspheres for periodontal tissue engineering
}

\section{Zeliha Soran, R. Seda Tığlı Aydın \& Menemşe Gümüşderelioğlu}

To cite this article: Zeliha Soran, R. Seda Tığlı Aydın \& Menemșe Gümüșderelioğlu (2012) Chitosan scaffolds with BMP-6 loaded alginate microspheres for periodontal tissue engineering, Journal of Microencapsulation, 29:8, 770-780, DOI: 10.3109/02652048.2012.686531

To link to this article: $\underline{h t t p}: / / d x . d o i . o r g / 10.3109 / 02652048.2012 .686531$

\section{曲 Published online: 21 May 2012.}

\section{एँ}

Submit your article to this journal $\pi$

Џلll Article views: 283

Q View related articles $\sqsubset$

Citing articles: 13 View citing articles 4 


\title{
Chitosan scaffolds with BMP-6 loaded alginate microspheres for periodontal tissue engineering
}

\author{
Zeliha Soran $^{1 \dagger}$, R. Seda Tiğlı Aydın ${ }^{2 \dagger}$ and Menemşe Gümüşderelioğlu ${ }^{1,2}$ \\ ${ }^{1}$ Department of Bioengineering, Hacettepe University, 06800 Beytepe, Ankara, Turkey and ${ }^{2}$ Department of Chemical \\ Engineering, Hacettepe University, 06800 Beytepe, Ankara, Turkey
}

\begin{abstract}
The aim of this study is to develop an effective growth factor releasing scaffold-microsphere system for promoting periodontal tissue engineering. Bone morphogenetic protein-6 (BMP-6)-loaded alginate microspheres in narrow size distribution were produced by optimising electrospraying conditions. The addition of these microspheres to chitosan gels produced a novel scaffold in which not only the pore sizes and interconnectivity were preserved, but also a controlled release vehicle was generated. Loading capacity was adjusted as $50 \mathrm{ng}$ or $100 \mathrm{ng}$ BMP- 6 for each scaffold and the controlled release behaviour of BMP-6 from chitosan scaffolds was observed during seven days. Cell culture studies were carried out with rat mesenchymal stem cells derived from bone marrow in three groups; chitosan scaffolds, chitosan scaffolds containing BMP-6loaded alginate microspheres and chitosan scaffolds with free BMP-6 in culture medium. Results showed that controlled delivery of BMP-6 from alginate microspheres has a significant effect on osteogenic differentiation.
\end{abstract}

Keywords: periodontal tissue engineering, BMP-6, chitosan scaffold, alginate microspheres, mesenchymal stem cells

\section{Introduction}

Periodontitis is a chronic inflammatory disease that results in the destruction of periodontium layer, which is a very important component of supporting tissues of the teeth (Renvert and Persson, 2004; Izumi et al., 2011). Moreover, it is also related with different systemic diseases such as respiratory system diseases, diabetes, osteoporoses and heart vessel diseases (Amar and Han, 2003). Conventional periodontal treatment is generally insufficient to regenerate the damaged tissues because of the complex structure of periodontitis layer. To handle this problem, a new approach, tissue engineering, is come up with to facilitate predictable periodontal regeneration in the last decade. However, the success of regenerating desired tissue requires appropriate selection of biocompatible scaffold as well as biological mediators like growth factors to coordinate cellular activities.

For periodontal regeneration, various growth factors can be used, e.g. bone morphogenetic proteins (BMPs), transforming growth factor beta, fibroblast growth factor, insulin like growth factor and platelet derived growth factor (Kaigler et al., 2006; Nakahara, 2006; Akman et al., 2010a). Among these, due to the periodontal differentiation ability, BMP group is preferred more than others. In literature, especially BMP-2, $-4,-7$ and -12 have been studied for both bone tissue and periodontal hard tissue regeneration (Nakashima et al., 2003). However, there are few studies about BMP-6 and its periodontal differentiation ability. One of these studies indicates the enhancement capacity of BMP-6 for the periodontal bone tissue formation (Huang et al., 2005). The other reports that BMP-6 is an appropriate biosignal for periodontal applications (Lee et al., 2010). Friedman and his colleagues reported that BMP-6 has more potential on the regulation of mesenchymal stem cells compared with BMP-2, BMP-4 and BMP-7 (Friedman et al., 2006). In another study, Akman et al. (2010b) reported that sustained release of the BMP-6 increases the osteogenic differentiation. All these results suggested that the delivery of BMP-6 increases the effect

Address for correspondence: Dr. M. Gümüşderelioğlu, Department of Bioengineering, Hacettepe University; Department of Chemical Engineering, Hacettepe University, 06800 Beytepe, Ankara, Turkey. Tel: 90-312-2977447. Fax: 90-312-2992124. E-mail: menemse@hacettepe.edu.tr

†Current addresses: Z. Soran, Bilkent University, Institute of Materials Science and Nanotechnology, 06800 Ankara, Turkey; Dr. R. Seda Tiğlı Aydın, Zonguldak Karaelmas University, Biomedical Engineering Department, 67100 Zonguldak, Turkey. 
of osteogenic regeneration and the controlled delivery of BMP-6 is required for the success of the desired applications.

Nowadays, micro- or nano-size particles have become the centre of interest for the delivery of various proteins or drugs (Amidi et al., 2010; Moebus et al., 2012). To date, a variety of techniques, including emulsification, droplet formation under simple gravity by dripping into multivalent cation solution and electrohydrodynamic atomisation, have been employed for fabrication of microcarriers (Salib et al., 1978; Suksamran et al., 2009; Voo et al., 2011). Although first two methods are most widely used, their important drawbacks are the difficulties to control the size and size distribution of the produced microspheres (Li et al., 2009). Electrospraying, based on electrohydrodynamic atomisation, is a new technique involving the ejection of micro/ nano-sized droplets instead of nano-jet from the Taylor Cone using electrical field (Bock et al., 2011). Although it has advantages such as small and monosized microsphere production, the biggest challenge of this technique is optimisation problems. It is reported that applied voltage, flow rate, nozzle-collector distance, polymer concentration, collector solution concentration, geometry of electrode and conductivity of polymer solution are important parameters that affect the microbead diameter (Xie and Wang, 2007a, 2007b; Sill and Recum, 2008). An electrospraying set-up, which is similar to electrospinning system, basically composed of an automatic syringe pump, voltage supply unit and collector stage. In this system, polymer solution fluxed at desired flow rates forms small droplets because of the voltage difference between the syringe nozzle and collector solution consisting of multivalent cations to crosslink the polymer (Xie and Wang, 2007a, 2007b; Mejia et al., 2009). For the production of such microspheres, both natural polymers and synthetic polymers can be used. Alginate is a natural linear binary co-polymer derived from seaweed. It is chemically composed of $\beta$-D-mannuronic (M) and $\alpha$-Lguluronic $(\mathrm{G})$ acids with a variation of sequential arrangement depending on their source. Due to its biocompatibility, non-toxic features and cheapness, alginate is widely used in different applications (Tığlı and Gümüşderelioğlu, 2009). It is also used for microcarrier production because of its gelation behaviour in the presence of multivalent cations like as $\mathrm{Ca}^{2+}, \mathrm{Ba}^{2+}$ and $\mathrm{Cu}^{2+}$. In the presence of multivalent cations, chelation occurs between the cations and carboxyl groups of $\alpha$-L-guluronic (G) acid. In general, $\mathrm{CaCl}_{2}$ solution is preferred for gelation owing to its non-toxic properties (Jay and Saltzman, 2009). In crosslinking reaction between sodium alginate and $\mathrm{CaCl}_{2}, \mathrm{Ca}^{2+}$ ions displace with sodium ions $\left(\mathrm{Na}^{+}\right)$and associate with blocks of $\mathrm{G}$ monomers to form bridges connecting separate polymer chains (Ciofani et al., 2007).

Although a limited number of studies that are investigated the BMP- 6 and its periodontal differentiation potential (Huang et al., 2005; Akman et al., 2010b; Lee et al., 2010); the protection and prolongation of its activity in the defect side is challenging for related periodontal tissue engineering applications. In order to provide prolonged activity of a number of growth factors, recent attempts have been concentrated on the combination of 3-D scaffolds with controlled delivery systems, e.g. micro and nano particles or spheres (Yılgör et al., 2009). However, it is still unknown whether a combination of the use of BMP-6 carrying micro/nano particles and a porous scaffold might substantially improve bone-forming efficacy. This is why, in this study, we decided to develop a novel effective BMP-6 releasing system which consists of chitosan scaffold and alginate microspheres. To achieve this purpose, we first prepared alginate microspheres by electrospraying technique and then we optimised synthesising conditions to obtain microparticles in the desired size range, narrow size distribution and mechanical stability. After microsphere characterisation studies, BMP-6-loaded alginate microcarriers were prepared and a novel porous chitosan scaffold including BMP6 -loaded alginate microspheres were produced by the freeze-drying method. By using this system, we investigated BMP-6 release from scaffolds mimicking natural environment. Cell culture studies were performed with rat bone marrow-derived mesenchymal stem cells (rBM-MSCs). Cell proliferation and differentiation to bone on scaffolds were investigated by appropriate analyses.

\section{Materials and methods}

\section{Materials}

Chitosan derived from crab shell with a deacetylation degree (DD) of minimum 85\% was purchased from Aldrich (Mw: 190000-375000, Cat. No: 417963, Taufkirchen, Germany). Sodium alginate was obtained from Fluka AG (Mw: 120000-190000, Cat. No: 71240, Buchs, Switzerland). Recombinant human bone morphogenetic growth factor was obtained from R\&D Systems (Minneapolis, USA, Cat. No: 507-BP). Fluorescein 5(6)-isothiocyanate (FITC) were obtained from Sigma (Germany). Acetic acid (HPLC grade), ethanol (96\% v/v) and calcium chloride $\left(\mathrm{CaCl}_{2} \cdot 2 \mathrm{H}_{2} \mathrm{O}\right)$ were from Merck (Darmstadt, Germany). MTT (Thiazolyl Blue Tetrazolium Bromide) used in proliferation assay, propidium iodide, $p$-nitrophenyl-phosphate (pNPP), ethylene diamine tetra-acetic acid (EDTA), hexamethyldisilazane (HMDS), Triton X-100 and glutaraldehyde were obtained from Sigma (Germany). Dulbecco's Modified Eagles Medium F12 (DMEM F12), foetal bovine serum (FBS), penicillin/streptomycin solution, ascorbic acid, dexamethasone and $\beta$-glycerol phosphate used in cell culture studies were purchased from Sigma (Germany). Moreover, Dulbecco's phosphate buffered saline (DPBS) and Alexa Fluor 488 phalloidin were purchased from Molecular Probes (Invitrogen Co., California, USA).

\section{Preparation of empty and BMP-6-loaded alginate microspheres}

The particles were prepared by the electrospraying method in which sodium alginate was sprayed into $\mathrm{CaCl}_{2}$ solution. 
For this purpose, sodium alginate solution with a concentration of $2 \%(\mathrm{w} / \mathrm{v})$ was prepared by dissolving sodium alginate in ultra-pure water and filtered using $0.45 \mu \mathrm{m}$ filter (Millipore) in order to eliminate the impurities. Alginate solution was electrosprayed via syringe with $22 \mathrm{G}$ needle into 3\% (w/v) $\mathrm{CaCl}_{2}$ solution where microspheres were collected. At the end of $24 \mathrm{~h}$ cross-linking period, microspheres were taken away from the collector solution and washed with distilled water. For stabilisation, beads were immersed into $70 \%$ (v/v) ethanol for an hour. After discarding the ethanol, microspheres were freeze-dried (Christ, Osterode am Harz, Germany).

In the electrospraying set-up, flow rates (20, 40 and $60 \mathrm{~mL} / \mathrm{h})$ and potential difference $(6 \mathrm{kV}, 7,8$ and $10 \mathrm{kV})$ were varied. Additionally, different nozzle-collecting stage distances, i.e. 4, 8, 16 and $32 \mathrm{~cm}$, were studied. All parameters used in the electrospraying method were optimised and BMP-6-loaded alginate microspheres were obtained using the optimised conditions.

BMP-6-loaded alginate microspheres were synthesised by adding BMP-6 (2 $\mu \mathrm{g} / \mathrm{mL}$ in DPBS) solution into $2 \%(\mathrm{w} / \mathrm{v})$ alginate solution. By loading $1.5 \mathrm{mg}$ and $3.0 \mathrm{mg}$ microspheres into a scaffold, 50 and $100 \mathrm{ng}$ BMP-6 containing chitosan scaffolds were obtained, respectively.

\section{Encapsulation efficiency}

Labelling of the primary amine groups on BMP-6 was realised by dialysis tubing cellulose membrane technique (Feltkamp, 1970; Akman et al., 2010b). BMP-6 content of the Ca-alginate microspheres was determined by solving alginate microspheres loaded with FITC-labelled BMP-6 in $5 \mathrm{mM}$ EDTA solution and then exposing them to $37^{\circ} \mathrm{C}$ overnight in a shaking incubator. The samples were centrifuged $(12000 \mathrm{rpm}$ for $1.5 \mathrm{~min}$ ) to ensure that all the microspheres were degraded. Then, solution was filtered $(0.45 \mu \mathrm{m})$ and BMP-6 concentration was determined using fluorescence spectrophotometer (Varian, California, USA) by measuring absorption at $495 \mathrm{~nm}$ and emission at $528 \mathrm{~nm}$. By using this measured value, the loaded amount of BMP-6 in the microspheres was calculated. Then, the encapsulation efficiency of BMP-6 in microspheres was calculated from the ratio of the loaded amount of BMP- 6 in the microspheres to the initial amount of BMP- 6 that was added to the alginate solution.

\section{Preparation of chitosan scaffolds and incorporation of BMP- 6-loaded microspheres into chitosan scaffolds}

In this study, chitosan scaffolds were prepared according to the procedure previously described by our group (Tiğlı et al., 2007). In brief, chitosan solution in the concentration of $2 \%(\mathrm{w} / \mathrm{v})$ was prepared by dissolving chitosan flakes in $0.2 \mathrm{M}$ acetic acid during overnight by stirring. Chitosan solutions were poured into 24-well tissue-culture polystyrene (TCPS) dishes and they were frozen at $-20^{\circ} \mathrm{C}$ for $24 \mathrm{~h}$ and then, transferred into freeze-drier to obtain highly interconnected porous scaffolds. For stabilisation, lyophilised scaffolds were rehydrated in $96 \%(\mathrm{v} / \mathrm{v})$ ethanol overnight and then in $70 \%(\mathrm{v} / \mathrm{v})$ ethanol for $1 \mathrm{~h}$.

Incorporation of BMP-6-loaded alginate microspheres into the chitosan scaffolds was performed by the mixing technique. In this method, the prepared chitosan solution was homogeneously mixed with dried microspheres and then poured into 24-well TCPS. Chitosan and dried alginate microspheres were mixed with the ratio of 50:25 (w/w) and 50:50 (w/w) for 50 and $100 \mathrm{ng}$ BMP-6 loading per chitosan scaffold, respectively. Then, plates were frozen at $-20^{\circ} \mathrm{C}$ for $24 \mathrm{~h}$ and then freeze-dried at $-80^{\circ} \mathrm{C}$ for 4 days. Scaffolds were cut into discs in a diameter of $10 \mathrm{~mm}$ and thickness of $1 \mathrm{~mm}$. Average dry weight of each scaffold is approximately $3 \mathrm{mg}$.

\section{Characterisation of microspheres}

The diameter and size distribution of alginate microspheres prepared at different conditions were determined by inverted optical microscope (Olympus, Tokyo, Japan). Images of microspheres were taken under $4 \times$ optical magnification and approximately 100 particle diameters were measured from these photographs using computational Image J program (NIH, Bethesda, Maryland, USA). To acquire a clear morphologic image of the empty and BMP-6-loaded microspheres selected for cell culture studies were coated with gold palladium layer and observed under SEM (Zeiss Evo 50, Oberkochen, Germany). In addition, the presence of microspheres in scaffolds was observed by SEM photographs.

The swelling and degradation characteristics of alginate microspheres were investigated by placing dry microspheres in Petri dishes containing culture medium. Then, they were allowed to incubate in a humidified incubator (Heraus Instruments, Frankfurt, Germany) at $37^{\circ} \mathrm{C}$ and $5 \% \mathrm{CO}_{2}$ condition. The morphologies of microspheres were observed under inverted microscope at desired time periods.

\section{Release study}

\section{BMP-6 release from chitosan scaffolds}

In-vitro release studies were carried out with 50 and $100 \mathrm{ng}$ FITC-labelled BMP-6-loaded chitosan scaffolds in $2 \mathrm{~mL}$ Eppendorf tube with $0.1 \%(\mathrm{w} / \mathrm{v})$ sodium azide including PBS, at $37^{\circ} \mathrm{C}$ with $15 \mathrm{rpm}$ agitation. In the studies, chitosan scaffolds of $10 \mathrm{~mm}$ diameter and $1 \mathrm{~mm}$ thickness were used. At the specific time intervals, complete solution was removed and filtered with $0.45 \mu \mathrm{m}$ filter. BMP- 6 concentration was determined using fluorescence spectrophotometer by measuring absorption at $495 \mathrm{~nm}$ and emission at $528 \mathrm{~nm}$. Buffer solution in the Eppendorf tubes was replenished after each measurement. All experiments were performed in triplicates. 
Release kinetics

In-vitro release kinetics of BMP-6 from microsphere including scaffolds was evaluated by the KorsmeyerPeppas model using the following equation (Korsmeyer et al., 1983):

$$
\frac{M_{t}}{M_{\infty}}=k \cdot t^{n}
$$

where $M_{t}$ is the cumulative amount of protein released at time $t, M_{t} / M_{\infty}$ is the fraction of protein released, $t$ is the release time, $k$ is the specific constant of carrier and $n$ is an exponent which characterises the mechanism of diffusional release kinetics. The $n$ and $k$ values were determined from the initial portion of log-log plots of $M_{t} / M_{\infty}$ versus time. The slope of the linear curve gives the $n$ value and the release mechanism was determined from $n$ and $k$ values.

In-vitro cell culture studies

Isolated rBM-MSCs were obtained from Kocaeli University, Stem Cell and Gene Therapy Research and Application Center (Turkey). Differentiation potential and growth kinetics of rBM-MSCs were studied (Karaöz et al., 2009). It was demonstrated that cells expressed osteogenic, myogenic and neurogenic genes under basal conditions. Their findings indicated that BM-MSCs possess superior capacity towards osteogenic differentiation and therefore might be a good cell source for bone tissue engineering (Karaöz et al., 2009). Also, optical microscope and fluorescent microscope images demonstrated that cells get to gain extracellular structure at day 3 and turn spindle-like shape at day 7 (Figure 7(a)). In the experiments, cells were cultured in DMEM-F12 supplemented with $10 \%$ (v/v) FBS and 1\% penicillin-streptomycin. The cells were passaged with $0.25 \%$ trypsin-1\% EDTA when confluent layer was observed under optical microscopy. Throughout this study, cells were maintained at $37^{\circ} \mathrm{C}$ in a humidified $\mathrm{CO}_{2}$ (5\%) atmosphere (Heraus Instruments, Germany).

\section{Cell seeding and cultivation in chitosan scaffolds}

Sterilisation of tissue scaffolds is the major important issue for cell culture studies. In our study, two techniques, treatment with ethylene oxide (EtO) gas and $70 \%$ ethanol, were used for chitosan scaffold sterilisation. In the literature, although some studies report that EtO gas deforms the chitosan structure and damages its mechanical properties, most of them have not seen any negative effect on the structure (Hamilton et al., 2006). In this study, chitosan scaffolds sterilised with EtO gas gained a fragile structure and crumbled in few days after the culture medium was added. This is why, sterilisation was performed by $70 \%$ ethanol.

Prior to cell culture experiments, 24-well TCPS dishes precoated with Parafilm were soaked in $70 \%$ ethanol for three days and then they were placed under UV light for
$30 \mathrm{~min}$ for sterilisation. On the other side, chitosan scaffolds were soaked in $70 \%$ ethanol for $24 \mathrm{~h}$ and then, they were placed into the Parafilm-coated TCPS. After washing with sterile DPBS, scaffolds were immersed in conditioning medium for $24 \mathrm{~h}$ and exposed to UV light for $15 \mathrm{~min}$ before cell seeding. Cell suspensions in the density of $2.5 \times 10^{5} / \mathrm{mL}$ cells were injected into each chitosan scaffold groups, i.e. chitosan, chitosan with free BMP-6 in medium and chitosan with BMP-6-loaded alginate microsphere, and allowed to incubate in a humidified incubator $\left(37^{\circ} \mathrm{C}\right.$, $5 \% \mathrm{CO}_{2}$ ) for $2 \mathrm{~h}$. Finally, $1 \mathrm{~mL}$ of osteogenic medium was added on each scaffold and constructs were incubated in stationary conditions and medium was replenished every three days. Culture medium was supplemented with $10 \mathrm{mM} \beta$-glycerol phosphate, $50 \mu \mathrm{g}$ ascorbic acid-2phosphate and $10^{-8} \mathrm{M}$ dexamethasone to obtain osteogenic medium.

\section{Cell proliferation and viability $(\mathrm{MTT})$}

Cell viability on the chitosan scaffolds was assessed using the colorimetric indicator 3-(4,5-dimethylthiazol-2-yl)-2,5diphenyl-tetrazoliumbromide (MTT) assay at days 3, 5, 7 and 9. After the medium on the scaffolds was discarded, $60 \mu \mathrm{L}$ of MTT solution $(2.5 \mathrm{mg} / \mathrm{mL}$ in PBS) and $600 \mu \mathrm{L}$ of serum-free medium were added to each well, then incubated for $3 \mathrm{~h}$ at $37^{\circ} \mathrm{C}$. At the end of the incubation period, the medium was aspirated and scaffolds were transferred to another 24-well plate. Four hundred microlitres of isopropanol solution ( $3 \% \mathrm{w} / \mathrm{v}$ in distilled water) containing $0.04 \mathrm{M} \mathrm{HCl}$ was added to the scaffolds to dissolve the formazan crystals which are formed due to the reduction of MTT by mitochondria. Two hundred microlitres of supernatant was transferred to 96-well plate and the optical density was measured spectrophotometrically with a microplate reader (Asys UVM 340, Australia) at 540 and $690 \mathrm{~nm}$ reference wavelength. All experiments were performed in triplicates.

\section{Alkaline phosphatase activity}

Osteogenic differentiation was determined by alkaline phosphatase activity (ALP) measurements at the third week of incubation period (Suck et al., 2007). This is why, culture medium was discarded from well, scaffolds were rinsed twice in PBS and they were freeze-dried for two days. Then, they were cut down into small pieces with scissors, and were digested by sonication at $4{ }^{\circ} \mathrm{C}$ in the lysis buffer ( $1 \%$ Triton X-100, in $0.01 \% \mathrm{v} / \mathrm{v}$ PBS) for $30 \mathrm{~min}$. At the end of the incubation, cell lysates were centrifuged at $12000 \mathrm{rpm}$ for $10 \mathrm{~min}$ at $4^{\circ} \mathrm{C}$. ALP activity was assayed using pNPP as substrate. This is why, to each well of 96-well culture plates, $50 \mu \mathrm{L}$ of supernatant and $125 \mu \mathrm{L}$ of ALP solutions (56 mM 2-amino 2-methyl-1,3-propanediol, pH 9.8, and $1 \mathrm{mM} \mathrm{MgCl}_{2}$ containing $10 \mathrm{~mL}$ pNPP) were added and the mixture was incubated at $37^{\circ} \mathrm{C}$ for $30 \mathrm{~min}$. Then, $50 \mu \mathrm{L}$ of $2.5 \mathrm{M}$ sodium hydroxide $(\mathrm{NaOH})$ was added to the 
wells to stop the reaction. Hydrolysis of substrate to $p$ nitrophenol was measured spectrophotometrically at $405 \mathrm{~nm}$ using microplate reader (Asys UVM 340, Australia).

\section{von Kossa staining}

The mineralisation of cells was determined by the von Kossa analysis, which shows colour change related to mineralisation degree (Cheng et al., 2001). Scaffolds at the third week of culture were removed from the culture medium and washed once with PBS and then soaked in ice cold absolute ethanol for $20 \mathrm{~min}$ to fix the cells. After washing with deionised water, $5 \% \mathrm{AgNO}_{3}(0.5 \mathrm{~g} / \mathrm{mL})$ was added onto cells and incubated for $30 \mathrm{~min}$ in dark environment. Afterward, samples were washed with deionised water again and exposed to UV for $2 \mathrm{~min}$.

\section{Scanning electron microscopy}

Attachment and spreading of the mesenchymal stem cells were observed morphologically by scanning electron microscopy (SEM) (Zeiss Evo 50, Japan) for the fourth week of the incubation period. Therefore, scaffolds were gently washed with PBS (pH 7.4) and $0.5 \mathrm{~mL}$ of $3 \%(\mathrm{v} / \mathrm{v})$ glutaraldehyde solution in PBS was added for $30 \mathrm{~min}$ to fix the cells. Dehydration was performed by serial incubation of scaffolds with $30 \%, 50 \%, 70 \%, 90 \%$ and $100 \%$ (v/v) ethanol for 2 min each and then they were rinsed with HMDS for $5 \mathrm{~min}$ at room temperature. SEM images were obtained after samples were coated with gold palladium.

\section{Statistical analysis}

All data are expressed as means \pm standard deviations of three similar experiments carried out in triplicate. Statistical analysis was performed by one-way analysis of variance in conjunction with Tukey's post-hoc test for multiple comparisons using SPSS Version 9.0 Software.

\section{Results and Discussion}

\section{Production of alginate microspheres}

Although there are several methods, e.g. emulsification, emulsification/internal gelation, water/oil/water emulsification, electropsraying, etc., for the production of microparticles, microsphere production methods are still under investigation since adjustment of one parameter usually results in complicated, often unpredictable, effects on the final microsphere properties (Hamilton et al., 2006; Voo et al., 2011). Therefore, optimisation of the microsphere preparation process is critical and inherently difficult. Electrospraying method, which basically includes a liquid delivery system (pump), a needle with high-electric potential and a grounded electrode which is in a short distance away from the needle, has the ability to easily produce monodisperse particles in different sizes. Besides, one of the attractive features of this method is the possibility of successful protein encapsulation (Jaworek, 2008; Ye et al., 2010).

It has been clearly demonstrated previously that applied voltage, emulsion flow rate, polymer concentration and the type of solvent affect the property of microspheres (Xie and Wang, 2007a, 2007b; Ye et al., 2010). In our study, 2\% (w/v) alginate solution was electrosprayed under different voltages $(6,7,8,9$ and $10 \mathrm{kV})$ for various flow rates $(20,40$ and $60 \mathrm{~mL} / \mathrm{h})$ and for different nozzle-collector distances $(4,8$, 16 and $32 \mathrm{~cm}$ ). At lower than $6 \mathrm{kV}$, the effect of electrical potential could not be observed and alginate droplets, approximately $1 \mathrm{~mm}$ in diameter, were formed. In addition, potential difference that is higher than $10 \mathrm{kV}$ caused shortcircuit due to the presence of a ring electrode. Produced microspheres were observed under optical microscope and their diameters were measured using Image $J$ software. Except $9 \mathrm{kV}$, other voltage values exhibited non-uniform size and broad size distribution at $20 \mathrm{~mL} / \mathrm{h}$ flow rate. At $40 \mathrm{~mL} / \mathrm{h}$ flow rate, 6 and $10 \mathrm{kV}$ applied voltages caused broad size distribution. Although microspheres prepared at 8 and $9 \mathrm{kV}$ had narrow size distribution, their diameters ( $>400 \mu \mathrm{m}$ ) were bigger than that of microspheres prepared at $20 \mathrm{~mL} / \mathrm{h}$. Finally, flow rate was changed as $60 \mathrm{~mL} / \mathrm{h}$ and the results demonstrated that 6,7 and $9 \mathrm{kV}$ voltages caused non-uniform size and at $10 \mathrm{kV}$ spherical form of particles was destroyed. Consequently, conditions of $20 \mathrm{~mL} / \mathrm{h}$ flow rate at $9 \mathrm{kV} ; 40 \mathrm{~mL}$ flow rate at $7 \mathrm{kV}$ and $60 \mathrm{~mL} / \mathrm{h}$ flow rate at $8 \mathrm{kV}$ were chosen to have uniform size and narrow size distribution. Average diameters of microspheres which are prepared in different electrospraying conditions, shown in Table 1. It was seen that diameters of microspheres varied between 250 and $400 \mu \mathrm{m}$. However, higher flow rates resulted in relatively smaller microspheres. In the literature, it was reported that flow rate increment causes higher dripping frequency when the nozzle voltage is larger than $4 \mathrm{kV}$, and thus smaller microbeads and conelike structures were observed. Also, it was reported that microsphere size decreases with increasing voltage values in the presence of ring electrode (Xie and Wang, 2007a) and it increases with the increase of nozzle-collector distance (Xie and Wang, 2007a), similar with our results. As could be seen from Table 1 where average diameters of microspheres are shown, microspheres synthesised in conditions of $40 \mathrm{~mL} / \mathrm{h}, 7 \mathrm{kV}, 8 \mathrm{~cm}$ (Group II-b) and $60 \mathrm{~mL} / \mathrm{h}, 8 \mathrm{kV}, 4 \mathrm{~cm}$ (Group III-a) were identified as the smallest particles; however, their size distributions were very wide. On the other hand, both size and size distribution was optimum at $20 \mathrm{~mL} / \mathrm{h}, 9 \mathrm{kV}, 32 \mathrm{~cm}$ (Group I-d) with a mean diameter of $391 \mu \mathrm{m}$ and at $60 \mathrm{~mL} / \mathrm{h}, 8 \mathrm{kV}, 16 \mathrm{~cm}$ (Group III-c) with a mean diameter of $360 \mu \mathrm{m}$. Some of the optical images of alginate microspheres are illustrated in Figure 1. SEM photographs of alginate microspheres belonging to Group II-b and Group III-c were also shown in Figure 2(a) and (b), respectively. Due to the vacuum application during gold coating, the alginate microspheres were shrunk. However, spherical morphology and uniform size of Group III-c microparticles were shown clearly. 
Table 1. Average diameters of microspheres produced in different operation conditions.

\begin{tabular}{cccccc}
\hline & Group I & Average diameter $(\mu \mathrm{m})$ & Group II & Average diameter $(\mu \mathrm{m})$ & Average diameter $(\mu \mathrm{m})$ \\
\hline a & $20 \mathrm{~mL} / \mathrm{h} ; 9 \mathrm{kV} ; 4 \mathrm{~cm}$ & $390 \pm 48$ & $40 \mathrm{~mL} / \mathrm{h} ; 7 \mathrm{kV} ; 4 \mathrm{~cm}$ & $301 \pm 113$ & $60 \mathrm{~mL} / \mathrm{h} ; 8 \mathrm{kV} ; 4 \mathrm{~cm}$ \\
$\mathrm{~b}$ & $20 \mathrm{~mL} / \mathrm{h} ; 9 \mathrm{kV} ; 8 \mathrm{~cm}$ & $350 \pm 77$ & $40 \mathrm{~mL} / \mathrm{h} ; 7 \mathrm{kV} ; 8 \mathrm{~cm}$ & $252 \pm 105$ & $60 \mathrm{~mL} / \mathrm{h} ; 8 \mathrm{kV} ; 8 \mathrm{~cm}$ \\
$\mathrm{c}$ & $20 \mathrm{~mL} / \mathrm{h} ; 9 \mathrm{kV} ; 16 \mathrm{~cm}$ & $387 \pm 16$ & $40 \mathrm{~mL} / \mathrm{h} ; 7 \mathrm{kV} ; 16 \mathrm{~cm}$ & $350 \pm 54$ & $60 \mathrm{~mL} / \mathrm{h} ; 8 \mathrm{kV} ; 16 \mathrm{~cm}$ \\
$\mathrm{~d}$ & $20 \mathrm{~mL} / \mathrm{h} ; 9 \mathrm{kV} ; 32 \mathrm{~cm}$ & $387 \pm 13$ & $40 \mathrm{~mL} / \mathrm{h} ; 7 \mathrm{kV} ; 32 \mathrm{~cm}$ & $391 \pm 17$ & $361 \pm 10$ \\
\hline
\end{tabular}
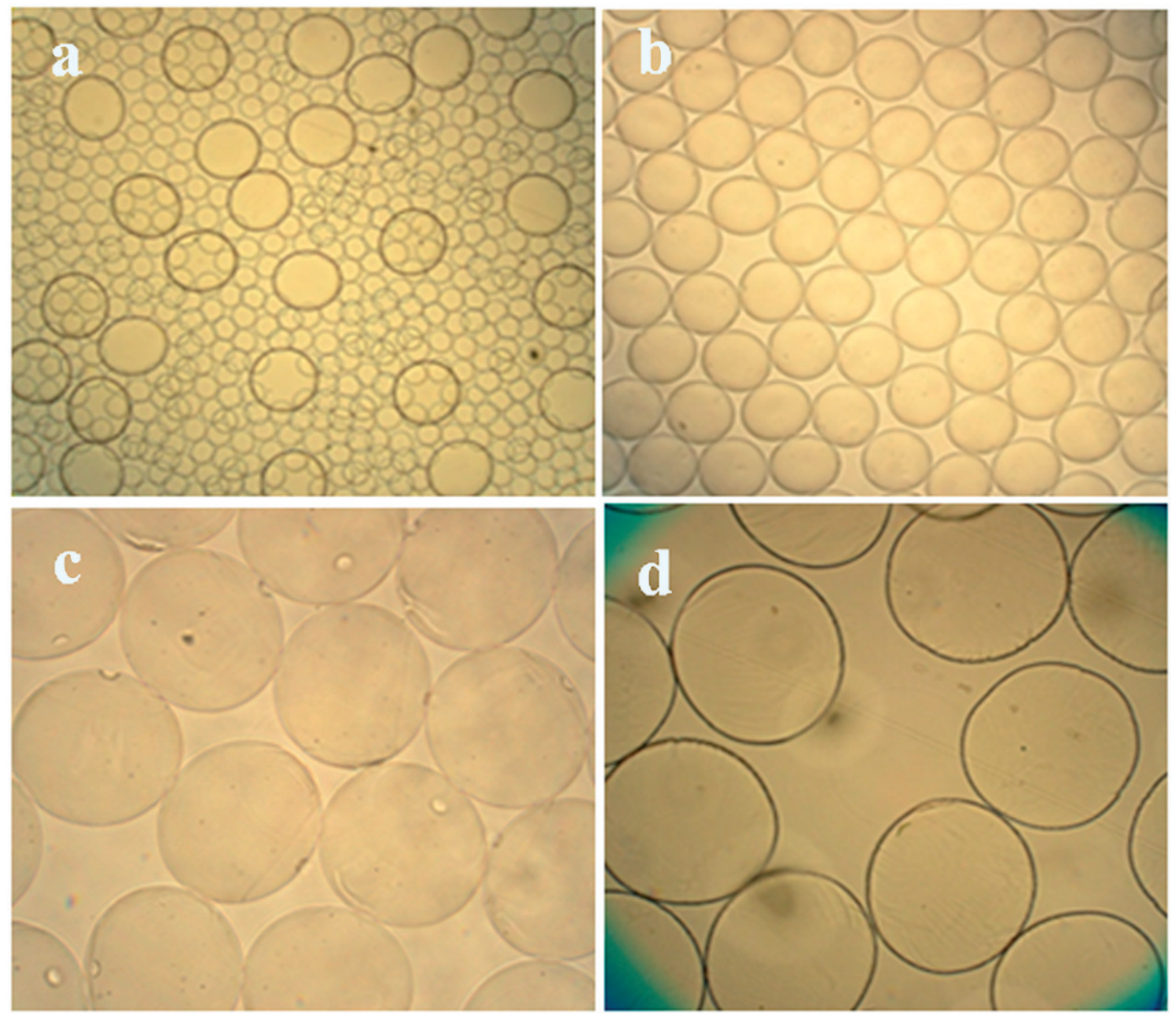

Figure 1. Optical images of alginate microspheres prepared at following conditions: (a) $60 \mathrm{~mL} / \mathrm{h}, 8 \mathrm{kV}, 4 \mathrm{~cm}$ (Group III-a) $(4 \times)$, (b) $60 \mathrm{~mL} / \mathrm{h}, 8 \mathrm{kV}, 16 \mathrm{~cm}$ (Group III-c) (4×), (c) $60 \mathrm{~mL} / \mathrm{h}, 8 \mathrm{kV}, 16 \mathrm{~cm}$ (Group III-c) (10×) and (d) BMP-6 loaded alginate microspheres (Group III-c) $(10 \times$ ).

Swelling and biodegradation behaviour of microcarriers are critical features for cell culture studies. So, these characteristics were identified to decide which group will be used in cell culture studies. Osmotic swelling of the microbeads in PBS at room temperature was evaluated by observing dimensional changes under microscope. The microparticles reached to equilibrium swelling in $15 \mathrm{~min}$ by absorbing water. Biodegradation results indicated that the particles of Group III-c were more stable than that of other groups listed in Table 1. Although their spherical forms started to change after $48 \mathrm{~h}$, still there were non-degraded microspheres at day 6. Eventually, the results obtained from optimisation studies demonstrated that microspheres produced in conditions of $60 \mathrm{~mL} / \mathrm{h}$ flow rate, $8 \mathrm{kV}$ applied voltage and $16 \mathrm{~cm}$ nozzle-collector distance (Group III-c) were highly monodispersed, stable and small in diameter. Therefore, the following studies were realised by using this group (Group III-c) of particles.

\section{Preparation of BMP-6 loaded alginate microspheres and scaffolds}

Selected group of particles (Group III-c) was loaded with BMP- 6 to have $100 \mathrm{ng}$ BMP- 6 per $3 \mathrm{mg}$ of alginate microsphere. Encapsulation efficiency, micro/nanoparticle size 

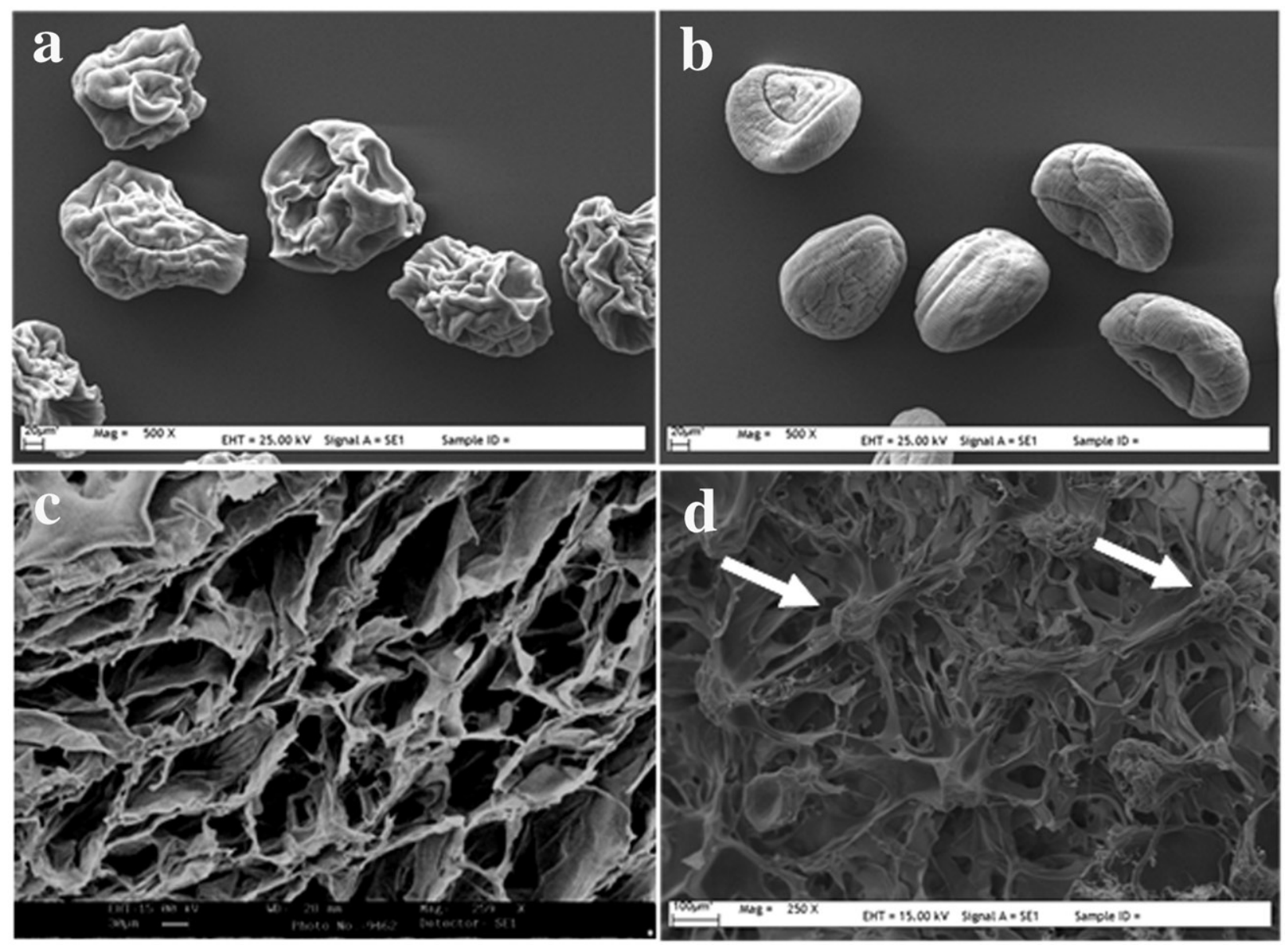

Figure 2. SEM images of (a) dried alginate microspheres of Group II-b, (b) dried alginate microspheres of Group III-c, (c) chitosan scaffold and (d) alginate microspheres incorporated chitosan scaffold (arrows indicate alginate microspheres).

and their swelling properties are leading parameters for release studies (Yao et al., 2008). This is why, encapsulation efficiency was determined and identified as $85.3 \%$. The image of BMP-6-loaded microspheres was shown in Figure $1(d)$. As seen from this image, there is no structural deformity due to the protein loading into alginate microspheres. Although measurements have shown a little increment in the diameter of loaded particles, it was not statistically significant.

It is known that scaffolds having the pore diameter greater than $100 \mu \mathrm{m}$ can enhance osteoblast's proliferation (Berkland et al., 2004). By taking into account the results of our previous study (Tiğl1 et al., 2007), porous chitosan scaffolds were prepared by applying freeze-drying method to the $2 \%(\mathrm{w} / \mathrm{v}$; weight of chitosan in volume of diluted acetic acid) chitosan (DD $>85 \%$ ) solution. In order to obtain BMP-6 including chitosan scaffolds, the scaffold preparation method was performed in the presence of BMP-6loaded alginate microspheres. The ratio of alginate microspheres to chitosan was adjusted to be $50: 50(\mathrm{w} / \mathrm{w})$ and 50:25 (w/w) for 100 and 50 ng BMP-6 loading per dry chitosan scaffold ( $3 \mathrm{mg}$ ), respectively. SEM images of empty scaffolds indicated highly interconnected structure with the pore size of $\sim 100 \mu \mathrm{m}$ (Figure 2(c)). The porosity of the scaffolds was calculated as $82.0 \%$. Figure 2(d) showed that alginate microspheres were successfully and homogenously distributed through the chitosan scaffold by maintaining the interconnected porous structure.

\section{In vitro release studies}

Release studies were carried out with FITC-labelled BMP6-loaded alginate microsphere including chitosan scaffolds and the cumulative release profile of BMP- 6 from scaffolds were shown in Figure 3. In-vitro studies demonstrated that BMP-6 release showed an initial burst in 50-ng-loaded groups. On the other hand, 100-ng-loaded BMP-6 groups exhibited better release profile. Diffusional release mechanism was determined from $n$ and $k$ values using Equation (1). In this situation, $n$ values between 0.45 and 0.89 show non-Fickian diffusion (anomolous), while $n=0.45$ for Fickian diffusion. Furthermore when $n=0.89$, the release rate is zero order, which means it is independent of time (case II transport) and super case II transport is apparent when $n>0.89$ (Peppas and Brannon-Peppas 1994). The calculated $n$ values for 50 and $100 \mathrm{ng}$ BMP-6-loaded scaffolds were 1.79 and 0.68 , respectively. These results demonstrated that low BMP-6-loaded group showed burst effect and super case II transport mechanism. On the other hand, 100-ng-loaded group indicated anomalous release mechanism, which shows balance between swelling and the release kinetics of the system. 


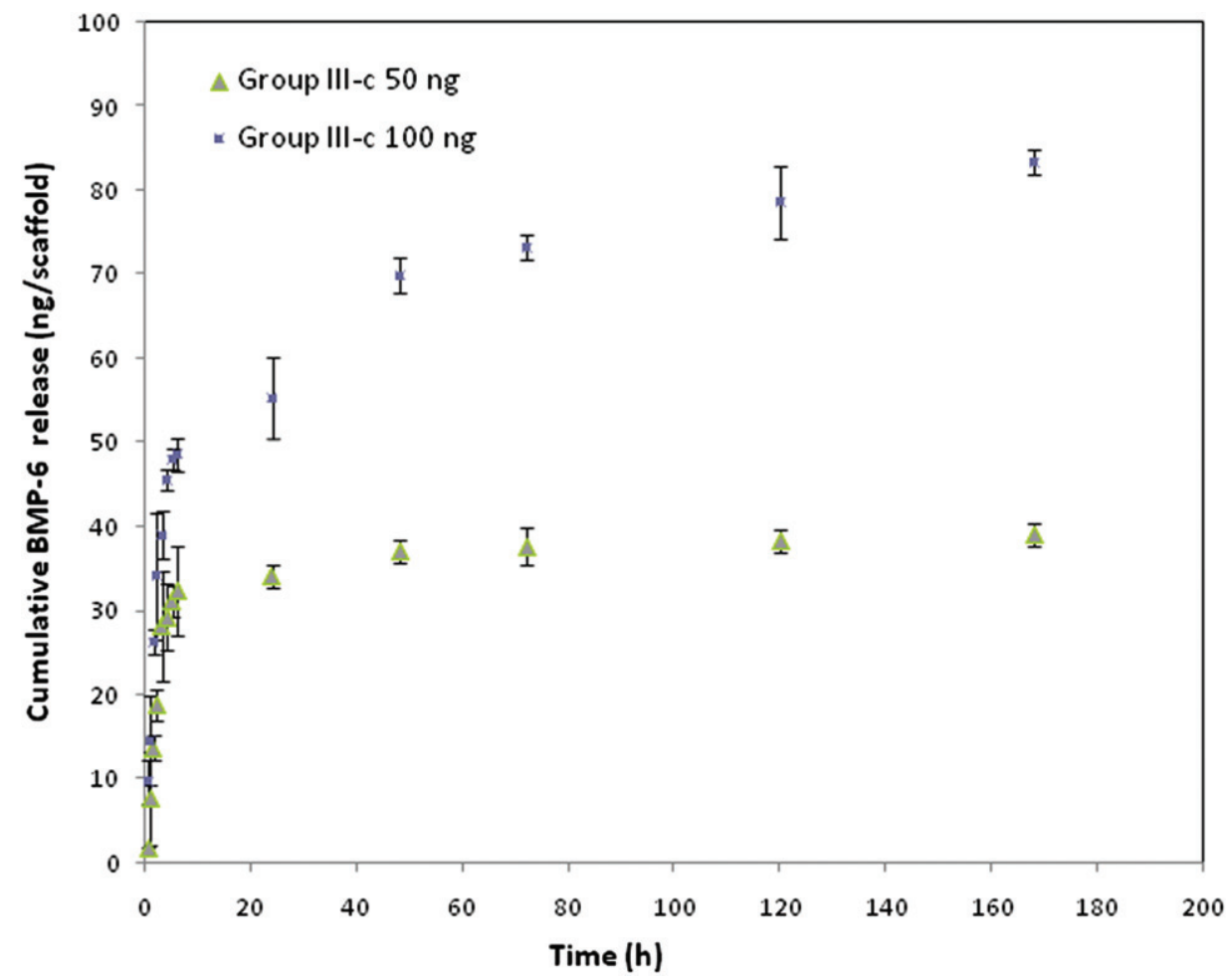

Figure 3. Cumulative release of BMP-6 from 50 and 100 ng BMP-6-loaded alginate microspheres (Group III-c) incorporated within chitosan scaffolds.

These results indicated that $100 \mathrm{ng}$ is the optimum quantity of BMP-6 to enhance osteogenesis, as reported in another study (Grasser et al., 2007).

The release from the microspheres probably takes place first into the pores present in scaffold and this prolongs the release of the molecules from the fibrous scaffold. Also, although alginate is a natural protein, it is also known as rapid biodegradable material. This study demonstrated that biodegradation rate of alginate microspheres decreased when they incorporated into the scaffolds. Eventually, it was decided to the $100 \mathrm{ng} / \mathrm{scaffold}$ loading amount and cell culture studies were carried out with this system.

\section{Cell culture studies}

\section{Proliferation of rBM-MSCs on chitosan scaffolds}

Previously, the success of BMP-6 with preosteoblastic MC3T3 cells for bone tissue engineering applications has been proved. Akman et al. (2010b) demonstrated that loading of BMP-6 into chitosan scaffolds increased the osteoblastic activity compared to results achieved from the direct addition of free BMP-6 to cultures containing cells and unloaded chitosan scaffolds. By taking into account these results, in this study, we basically evaluated the effects of released BMP-6 from a novel system, BMP-6loaded microspheres incorporated chitosan scaffolds, on mesenchymal stem cells for periodontal tissue regeneration. To evaluate the proliferation of mesenchymal stem cells within the scaffolds, four groups were fabricated as only chitosan scaffold (Scaffold), chitosan scaffold with free BMP-6 in culture (Free BMP-6), chitosan scaffold including BMP-6-loaded alginate microspheres (scaffold + microsphere) and control group (TCPS). MTT assays were performed at days 3, 5, 7 and 9 (Figure 4) using the method of Gerlier and Thomasset (1986). Although all groups demonstrated increasing cell proliferation at day 3, results suggest that cell attachment and proliferation were greater in scaffolds than that of TCPS. Compared to TCPS, cell proliferation was significantly higher in other groups at day 5. On day 7, all groups, compared with TCPS, demonstrated increasing proliferation. As seen from Figure 4, the mitochondrial activity of cells on scaffold + microsphere group was significantly higher compared with both chitosan and free BMP-6 groups. After seventh day of incubation, optical densities were decreased in all groups but microsphere including group was still significantly higher than TCPS and only chitosan scaffold at day $9(p<0.001)$. Optical density is also significantly higher than free BMP-6 including group $(p<0.01)$. In Figure 4 it is seen that, cell proliferation in free BMP-6 group was highest at day 3 but decreased at day 7 . On the other hand, in scaffold + microsphere group, cell proliferation was increased slowly and maximum level was observed at day 7 . This result suggests that the controlled release of the protein has a significant effect on proliferating cells.

In the light of these data, scaffold including groups supported cell proliferation more than TCPS group as well as shown in our previous study (Akman et al., 2010b). Moreover, with this study not only the effect of BMP-6 on 


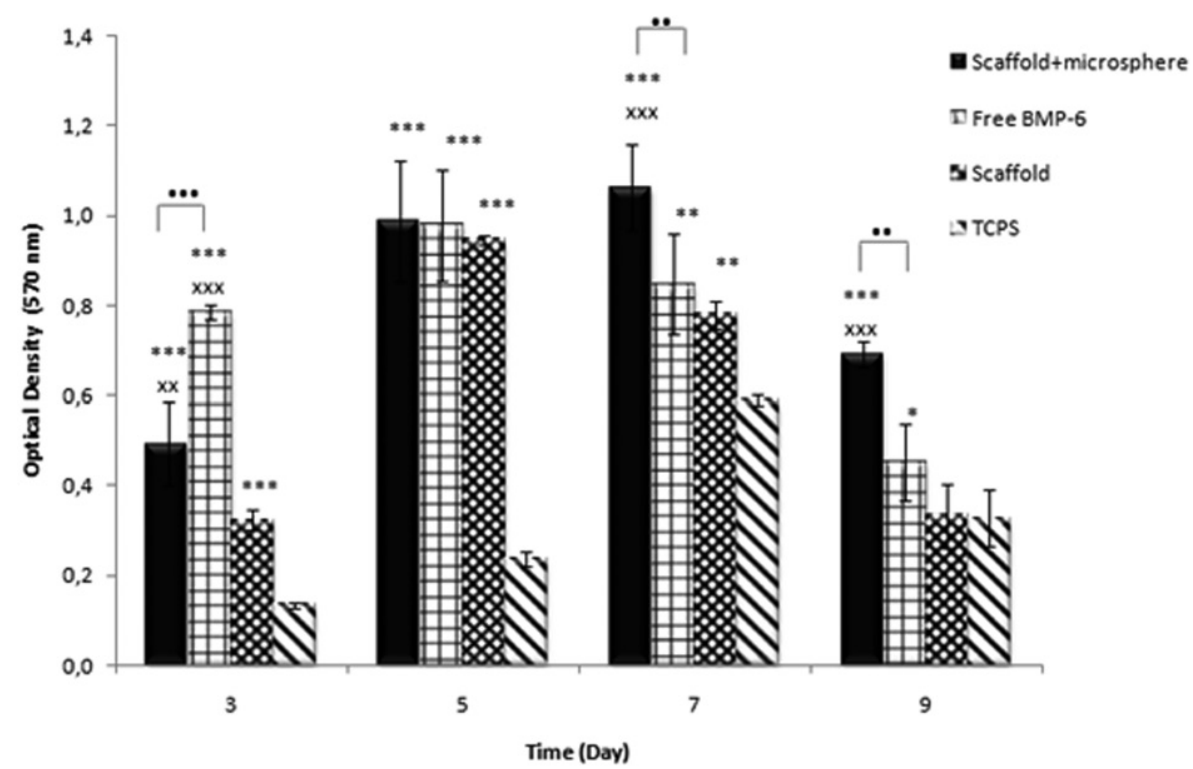

Figure 4. MTT assay of MSCs seeded on BMP-6-loaded alginate incorporated chitosan scaffold (scaffold + microsphere), chitosan scaffolds with free BMP6 in medium (Free BMP-6), chitosan scaffold (scaffold) and TCPS. (Statistical significance, $n=4$, TCPS is control group * $p<0.05$; ** $p<0.01$; *** $p<0.001$; Chitosan is control group $\mathrm{xx} p<0.01 ; \mathrm{xxx} p<0.001$; Free BMP-6-loaded chitosan is conrol group. $p<0.01 ; \ldots p<0.001$ ).

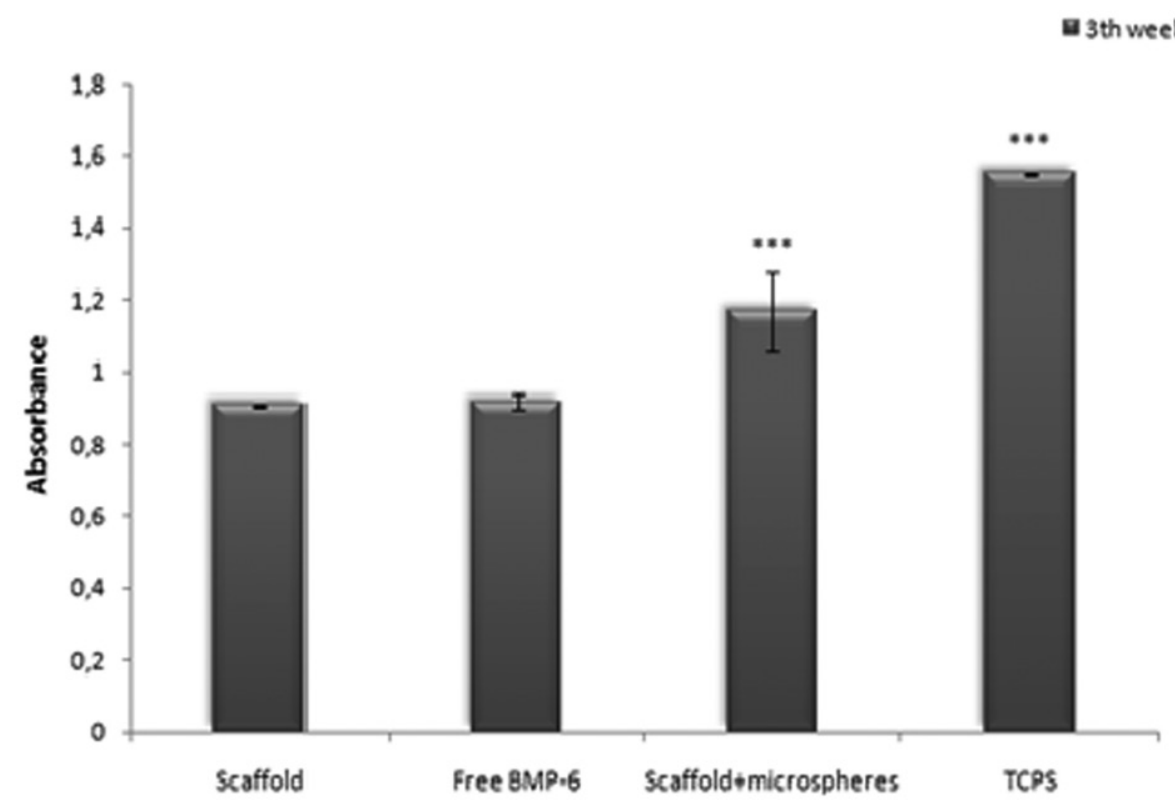

Figure 5. ALP activities of MSCs. (Statistical significance, $n=4,{ }^{* * *} p<0.001$; chitosan scaffold is control group.)

osteogenic differentiation, but also the proliferation effect on rBM-MSCs was shown. Friedman et al. (2006) investigated BMP-6 and mesenchymal stem-cell relationship and reported that regulator features of BMP-6 are better than BMP-2, -4 and -7 on MSCs. Also, MTT assay indicated that the dramatic increment of the cell proliferation was observed in the groups including BMP-6.

\section{ALP activities}

Differentiation of MSCs was assessed by ALP activity. Figure 5 demonstrated the ALP activity of mesenchymal stem cells on scaffolds at week 3. ALP activity results showed that there were no statistically significant differences between the ALP activities of the cells in the chitosan and free BMP-6 group during the experimental period $(p>0.05)$. On the other hand, osteogenic differentiation was significantly greater in alginate microsphere including scaffolds. Differences were statistically significant at the third week $(p<0.001)$. Comparison between free BMP-6 and BMP-6 encapsulated microsphere including groups indicated that microcarriers take a major role on differentiation of the cells due to controlled delivery of biosignal molecule. ALP result is found corresponded with MTT assay results. 


\section{Mineralisation assay}

The von Kossa analysis was used for the identification of matrix calcification within the cell-seeded scaffolds. Results taken at the third week of incubation are demonstrated in Figure 6. Calcification, which is an indicator of osteogenic differentiation, was determined from colour change to brown-black. Different degrees of staining were observed between protein including groups. Although both of BMP6-treated scaffolds showed positive staining, colour change

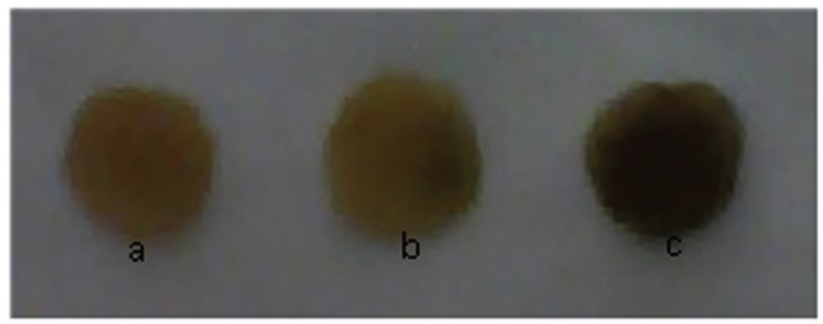

Figure 6. von Kossa staining of chitosan scaffolds at the third week. (a) Chitosan scaffold, (b) chitosan scaffold with free BMP-6 in medium and (c) BMP-6-loaded alginate microsphere incorporated within chitosan scaffold. of BMP-6 including alginate microsphere-loaded chitosan scaffold was more evident compared to free BMP-6-loaded scaffolds (Figure 6(b) and (c)). These results supported the results of ALP activity at the third week.

\section{Microscopic imaging of cells within the scaffolds}

Primary mesenchymal stem cells obtained from rat bone marrow were characterised for cell culture studies and fluorescence staining of cells at day 16 was shown in Figure 7(a). As seen from the image, cell morphology was in spindle-like shape as expected. The SEM images of cells in scaffolds (Figure 7(b)) illustrated the cellular attachments in sponge-like chitosan scaffolds and cell extending towards the pores on walls. Moreover, as seen from Figure 7(c) and (d), fibroblastic cell morphology clearly changed as a result of differentiation potential of cells in the presence of BMP-6. More importantly, SEM images of BMP-6 including alginate microsphere-loaded chitosan scaffolds revealed that cells have already synthesised extracellular matrix (ECM) and attached cells have covered a part of pores by spreading (Figure $7(d)$ ).
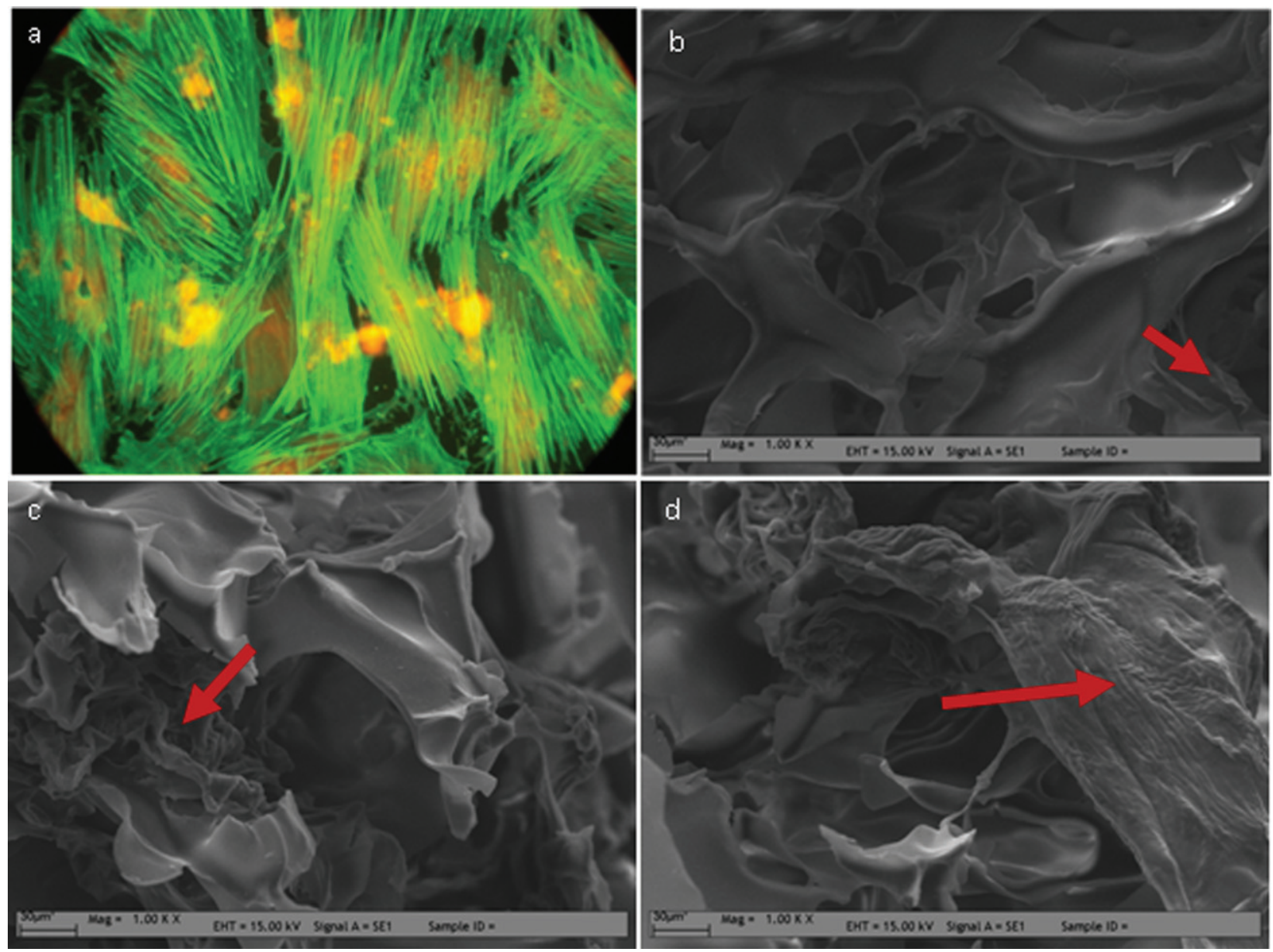

Figure 7. (a) Fluorescence microscope image of primary rat mesenchymal stem cells cultured on TCPS (second week, 20x) and SEM images of MSCs cultured on (b) chitosan scaffold, (c) chitosan scaffold with free BMP-6 in medium and (d) BMP-6-loaded alginate incorporated chitosan scaffold (1.00 KX) at the end of fourth week of incubation period. 


\section{Conclusion}

In this study, BMP-6 containing alginate microparticles in narrow size distribution and excellent spherical shape are formed by the electrospraying method in optimised conditions. The microparticles in a diameter of $360 \mu \mathrm{m}$ were combined with the chitosan scaffolds that were prepared by freeze-drying. Thus, a novel 3D construct carrying BMP6 delivery system was developed. The results of cell culture studies indicated that the combined system enhances the osteoblastic differentiation of bone marrow-derived rat mesenchymal stem cells by providing the controlled release of BMP-6. In conclusion, this system can be considered as an appropriate vehicle for possible periodontal tissue engineering applications.

\section{Acknowledgements}

This study was supported by grant (110M345) of the Scientific and Research Council of Turkey (TUBITAK).

\section{Declaration of interest}

The authors report no conflicts of interest. The authors alone are responsible for the content and writing of the article.

\section{References}

Akman AC, Tığlı RS, Gümüşderelioğlu M, Nohutcu RM. bFGF loaded Ha chitosan: A promising scaffold for periodontal tissue engineering. J Biomed Mater Res, Part A, 2010a;92:953-62.

Akman AC, Tiğlı RS, Gümüşderelioğlu M, Nohutcu RM. Bone morphogenetic protein 6 loaded chitosan scaffolds enhance the osteoblastic characteristics of Mc3t3 E1 cells. Artif Organs, 2010b;34:65-74.

Amar S, Han X. The impact of periodontal infection on systemic diseases. Med Sci Monit, 2003;9:RA291-9.

Amidi M, Mastrobattista E, Jiskoot W, Hennink WE. Chitosan-based delivery systems for protein therapeutics and antigens. Adv Drug Delivery Rev, 2010;62:59-82.

Berkland C, Kipper MJ, Narasimhan B, Kim K, Pack DW. Microsphere size, precipitation kinetics and drug distribution control drug release from biodegradable polyanhydride microspheres. J Controlled Release, 2004;94:129-41.

Bock N, Woodruff MA, Hutmacher DW, Dargaville TR. Electrospraying, a reproducible method for production of polymeric microspheres for biomedical applications. Polymers, 2011;3:131-49.

Cheng SL, Lai CF, Blystone SD, Avioli LV. Bone mineralization and osteoblast differentiation are negatively modulated by integrin $\alpha \mathrm{v} \beta 3$. J Bone Miner Res, 2001;16:277-88.

Ciofani G, Raffa V, Menciassi A, Micera S, Dario P. A drug delivery system based on alginate microspheres: Mass-transport test and in vitro validation. Biomed Microdevices, 2007;9:395-403.

Feltkamp T. Conjugation of fluorescein isothiocyanate to antibodies: II. A reproducible method. Immunology, 1970;18:875-81.

Friedman MS, Long MW, Hankenson KD. Osteogenic differentiation of human mesenchymal stem cells is regulated by bone morphogenetic protein-6. J Cell Biochem, 2006;98:538-54.

Gerlier D, Thomasset N. Use of MTT colorimetric assay to measure cell activation. J Immunol Methods, 1986;94:57-63.

Grasser WA, Orlic I, Borovecki F, Riccardi K, Simic P, Vukicevic S, Paralkar VM. Bmp-6 exerts its osteoinductive effect through activation of IgF-I and EgF pathways. Int Orthop, 2007;31:759-65.

Hamilton V, Yuan Y, Rigney D, Puckett A, Ong J, Yang Y, Elder S, Bumgardner J. Characterization of chitosan films and effects on fibroblast cell attachment and proliferation. J Mat Sci-Mat Med, 2006;17: 1373-81.
Huang KK, Shen C, Chiang CY, Hsieh YD, Fu E. Effects of bone morphogenetic protein 6 on periodontal wound healing in a fenestration defect of rats. J Periodontal Res, 2005;40:1-10.

Izumi Y, Aoki A, Yamada Y, Kobayashi H, Iwata T, Akizuki T, Suda T, Nakamura S, Wara-Aswapati N, Ueda M, et al. Current and future periodontal tissue engineering. Periodontology 2000, 2011;56:166-87.

Jaworek A. Electrostatic micro- and nanoencapsulation and electroemulsification: A brief review. J Microencapsulation, 2008;25:443-68.

Jay SM, Saltzman WM. Controlled delivery of vegf via modulation of alginate microparticle ionic crosslinking. J Controlled Release, 2009; 134:26-34.

Kaigler D, Cirelli JA, Giannobile WV. Growth factor delivery for ora and periodontal tissue engineering. Expert Opin Drug Deliv, 2006;3:647-62.

Karaöz E, Aksoy A, Ayhan S, Sarıboyacı AE, Kaymaz F, Kasap M. Characterization of mesenchymal stem cells from rat bone marrow: Ultrastructural properties, differentiation potential and immunophenotypic markers. Histochem Cell Biol, 2009;132:533-46.

Korsmeyer RW, Gurny R, Doelker E, Buri P, Peppas NA. Mechanisms of solute release from porous hydrophilic polymers. Int J Pharm, 1983;15:25-35.

Lee K, Silva E, Mooney D. Growth factor delivery-based tissue engineering: General approaches and a review of recent developments. J R Soc Interface, 2010;8:153-70.

Li BZ, Wang LJ, Li D, Bhandari B, Li SJ, Lan Y, Chen XD, Mao ZH. Fabrication of starch-based microparticles by an emulsification-crosslinking method. J Food Eng, 2009;92:250-4.

Mejia AF, He P, Luo D, Marquez M, Cheng Z. Uniform discotic wax particles via electrospray emulsification. J Colloid Interface Sci, 2009;334:22-8.

Moebus K, Siepmann J, Bodmeier R. Novel preparation techniques for alginate-poloxamer microparticles controlling protein release on mucosal surfaces. Eur J Pharm Sci, 2012;45, 3:358-66.

Nakahara T. A review of new developments in tissue engineering therapy for periodontitis. Dent Clin N Am, 2006;50:265-76.

Nakashima M, Tachibana K, Iohara K, Ito M, Ishikawa M, Akamine A. Induction of reparative dentin formation by ultrasound-mediated gene delivery of growth/differentiation factor 11. Hum Gene Ther, 2003;14:591-7.

Peppas NA, Brannon-Peppas L. Water diffusion and sorption in amorphous macromolecular systems and foods. J Food Eng, 1994;22:189-210.

Renvert S, Persson GR. Supportive periodontal therapy. Periodontology 2000, 2004;36:179-95.

Salib N, El-Menshawy M, Ismail A. Utilization of sodium alginate in drug microencapsulation. Pharm Ind, 1978;40:1230-4.

Sill TJ, von Recum HA. Electrospinning: Applications in drug delivery and tissue engineering. Biomaterials, 2008;29:1989-2006.

Suck K, Behr L, Fischer M, Hoffmeister H, Griensven MV, Stahl F, Scheper T, Kasper C. Cultivation of MC3T3 E1 cells on a newly developed material (Sponceram ${ }^{\circledR}$ ) using a rotating bed system bioreactor. J Biomed Mater Res A, 2007;80:268-75.

Suksamran T, Opanasopit P, Rojanarata T, Ngawhirunpat T, Ruktanonchai U, Supaphol P. Biodegradable alginate microparticles developed by electrohydrodynamic spraying techniques for oral delivery of protein. J Microencapsulation, 2009;26:563-70.

Tığlı RS, Karakeçili A, Gümüşderelioğlu M. In vitro characterization of chitosan scaffolds: influence of composition and deacetylation degree. J Mat Sci Mat Med, 2007;18:1665-74.

Tığlı RS, Gümüşderelioğlu M. Evaluation of alginate-chitosan semi IPNs as cartilage scaffolds. J Mat Sci: Mat Med, 2009;20:699-709.

Voo WP, Ravindra P, Tey BT, Chan ES. Comparison of alginate and pectin based beads for production of poultry probiotic cells. J Biosci Bioeng 2011;111:294-9.

Xie J, Wang CH. Electrospray in the dripping mode for cell microencapsulation. J Colloid Interface Sci, 2007a;312:247-55.

Xie J, Wang CH. Encapsulation of proteins in biodegradable polymeric microparticles using electrospray in the taylor cone jet mode. Biotechnol Bioeng, 2007b;97:1278-90.

Yao J, Kuang Lim L, Xie J, Hua J, Wang CH. Characterization of electrospraying process for polymeric particle fabrication. J Aerosol Sci, 2008;39:987-1002.

Ye M, Kim S, Park K. Issues in long-term protein delivery using biodegradable microparticles. J Controlled Release, 2010;146:241-60.

Yılgör P, Tuzlakoğlu K, Reis RL, Hasırcı N, Hasırcı V. Incorporation of sequential BMP-2/BMP-7 delivery system into chitosan-based scaffolds for bone tissue engineering. Biomaterials, 2009;30(21):3551-9. 